\title{
KONSEP WATERFRONT \\ PADA PERMUKIMAN ETNIS KALI SEMARANG
}

\author{
Ajeng Sarinastiti"), R. Siti Rukayah, Titin Woro Murtini \\ Program Studi Magister Teknik Arsitektur, Fakultas Teknik, Universitas Diponegoro, \\ Jl. Hayam Wuruk 5, Kampus Undip Pleburan, Semarang, Indonesia
}

\begin{abstract}
Abstrak
Kali Semarang sebagai sungai bersejarah di Semarang, dahulu memiliki fungsi transportasi yang membelah perekonomian dan pertahanan kota. Bermacam etnis pedagang tinggal di sekitarnya hingga daerah tersebut menjadi permukiman etnis. Contohnya Kampung Melayu, etnis Tionghoa pada Kampung Pecinan, etnis Arab pada Kampung Kauman, serta Kampung Sekayu. Dan juga Kawasan Kota Lama sebagai daerah bersejarah dalam masa pemerintahan Kota Semarang. Kali Semarang memberi pengaruh fungsi waterfront pada permukiman tersebut.Penelitian ini bertujuan untuk mengetahui konsep waterfront pada permukiman etnis Kali Semarang, yaitu Kampung Melayu, Kawasan Kota Lama, Kampung Pecinan, Kampung Kauman, dan Kampung Melayu. Diperlukan eksplorasi dan deskripsi keadaan yang mendalam untuk mengidentifikasikan informasi baru pada lokasi penelitian dengan konsep atau teori yang menjelaskan fenomena yang akan terjadi. Metode kualitatif rasionalistik digunakan dengan landasan teori mengenai waterfront dan permukiman etnis disertai dengan pengumpulan data melalui studi literatur dari berbagai sumber, observasi lapangan langsung, dan pertanyaan mendalam kepada key person. Hasil penelitian ini menunjukkan bahwa hanya Kampung Melayu dan Kawasan Kota Lama yang pada awal mulanya menggunakan konsep waterfront karena lokasinya merupakan kawasan pelabuhan, pergudangan, dan perdagangan. Kampung Pecinan sebagai kawasan perdagangan, serta Kampung Kauman dan Kampung Sekayu sebagai permukiman tidak menggunakan konsep waterfront.
\end{abstract}

Kata kunci: waterfront; permukiman etnis; Kali Semarang

\begin{abstract}
[Title: Waterfront Concept on Ethnic Settlement in Kali Semarang] Kali Semarang, as a historical river in Semarang, has function as transportation to support the economy and city. Many ethnic traders settled around, so that area becomes ethnic settlement, such as Kampung Melayu, Chinese ethnic in Kampung Pecinan, Arabian ethnic in Kampung Kauman, and Kampung Sekayu, and Kota Lama areas as historical area in Semarang's government era. The Kali Semarang giving influence of the waterfront function of those area. This paper purposes to understand waterfront concept of ethnicity settlement around Kali Semarang, such as: Kampung Melayu, Kawasan Kota Lama, Kampung Pecinan, Kampung Kauman, and Kampung Melayu. Exploration and deeper situations description are needed to identify new informations in respected location completed with concept or theories that explain the phenomenon. The qualitative rationalistic method is used for explaining theoritical basis regarding waterfront and ethnical settelement by data collecting through literature study, field observation, and key person question. The result of this research shows that Kampung Melayu and Kota Lama are pioneer to use the waterfront concept because of it location constitute as sea port area, warehouse, and commerce. Kampung Pecinan as a commerce area, Kampung Kauman and Kampung Sekayu, as settlement, did not use the waterfront concept.
\end{abstract}

Keywords : waterfront; ethnic settlements; Kali Semarang

\section{Pendahuluan}

Kali Semarang yang dahulu memiliki fungsi transportasi dengan membelah perekonomian dan pertahanan kota, memberi pengaruh terhadap

\footnotetext{
${ }^{*}$ Penulis Korespondensi.

E-mail: ajengsarinastiti15@gmail.com
}

permukiman yang dilaluinya. Konsep waterfront yang merupakan tempat terjadinya pertemuan antara daratan dan perairan (Breen, 1994) mulai muncul pada kawasan tersebut seiring dengan banyaknya pedagang dari berbagai daerah yang masuk dan tinggal di permukiman sekitar Kali Semarang. Mulanya berkembang dari arah perairan dan kemudian mulai 


\section{Teknik, 36 (2), 2015, 62}

ramai dikunjungi dan ditempati orang sehingga terjadi perluasan lokasi dan penyebaran ke arah daratan, lalu muncul sarana-sarana penunjang untuk melengkapi aktivitas di dalamnya (Wrenn, 1983). Hal tersebut yang membuat kawasan di sekitarnya menjadi permukiman etnis. Sebagai contohnya warga multietnis pada Kampung Melayu, warga etnis Tionghoa pada Kampung Pecinan, warga etnis Arab pada Kampung Kauman, dan Kampung Sekayu. Tak lupa Kawasan Kota Lama sebagai daerah bersejarah dalam masa pemerintahan Kota Semarang.

Kemudian disusul dengan munculnya beberapa jenis waterfront menurut fungsinya. Cultural waterfront yang memadai aktivitas budaya, pendidikan, dan ilmu pengetahuan. Environtment waterfront yang berupaya meningkatkan kualitas lingkungan. Historical waterfront yang dikembangkan ke arah konservasi bangunan sejarah. Mixed-used waterfront yang merupakan kombinasi dari perumahan, perkantoran, perdagangan, atau kebudayaan. Recreational waterfront yang menyediakan sarana rekreasi. Residential waterfront yang memadai permukiman, serta working waterfront yang memadai industri berat dan fungsi pelabuhan (Breen, 1996).

Jika dilihat pada masa kini, bangunan permukiman yang ada di sepanjang bantaran Kali Semarang ada yang memanfaatkan Kali Semarang sebagai muka bangunan sebagai nilai tambah, ada pula yang tidak memanfaatkannya. Berdasarkan hal tersebut maka penelitian ini dilakukan guna mengetahui penerapan konsep waterfront terhadap permukiman etnis bantaran Kali Semarang.

\section{Lokasi Penelitian}

Kota Semarang dengan keunikan topografi membuatnya memiliki banyak sungai. Salah satunya adalah Kali Semarang yang terletak pada Kecamatan Semarang Tengah dan Kecamatan Semarang Utara, Kota Semarang (Gambar 1).

Kali Semarang memiliki panjang 8,25 km Sungai ini dahulu mempunyai fungsi utama sebagai transportasi. Kapal-kapal pedagang masuk ke Kota Semarang melalui Pelabuhan Boom Lama kemudian menuju kota melalui Kali Semarang. Barang dagangan para pedagang tersebut diperjualbelikan di beberapa pasar sekitar Kali Semarang. Banyaknya pendatang yang datang dan menetap di Kota Semarang, menjadikan permukiman di sekitar Kali Semarang dihuni oleh bermacam etnis. Permukiman etnis yang menunjukkan kearifan lokal Kota Semarang itu antara lain Kampung Melayu, Kampung Pecinan, Kampung Kauman, dan Kampung Sekayu. Kali Semarang dengan fungsinya sebagai pertahanan kota juga melewati daerah bersejarah dalam pemerintahan Kota Semarang, yaitu Kota Lama.

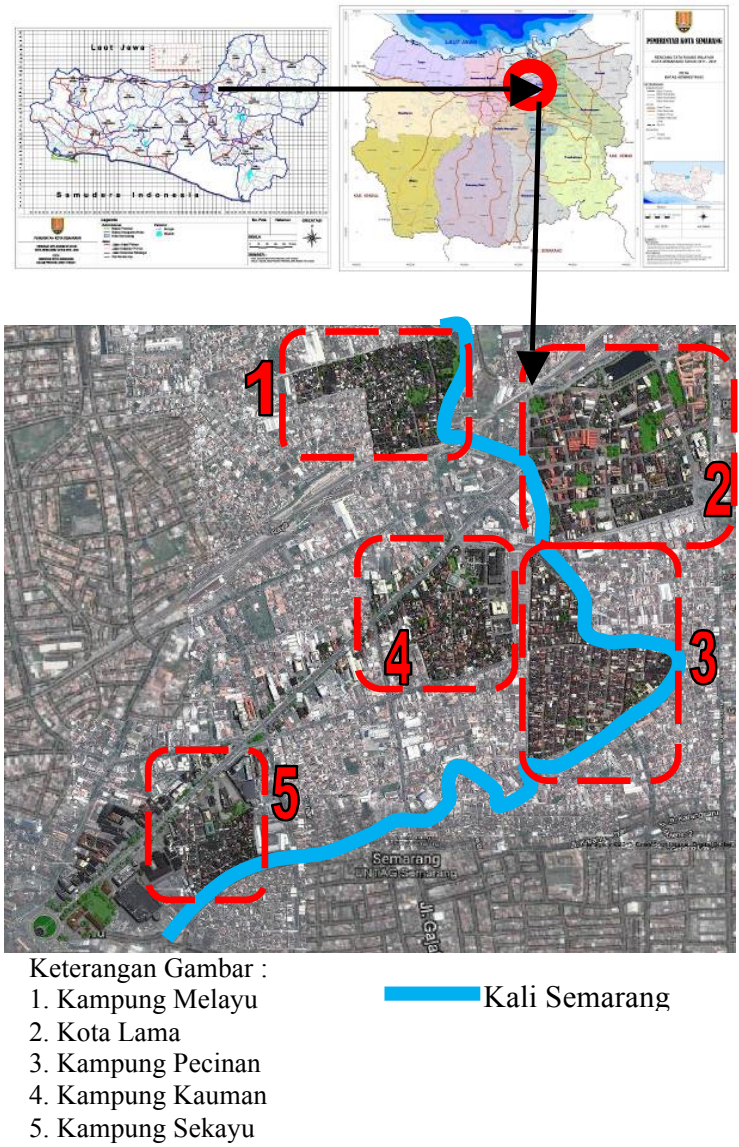

Gambar 1. Lokasi Permukiman Etnis Kali Semarang (DTK Semarang, 2014 dan Google Earth, 2013)

Telah dilaksanakan proyek normalisasi sepanjang Kali Semarang tahun 1980 dengan membuat jalan inspeksi sebesar 7 meter pada bantaran sungai dan mencanangkan konsep waterfront pada permukiman di bantarannya. Proyek ini telah berhasil menata Kali Semarang (Gambar 2) menjadi lebih bersih dan teratur. Beberapa bangunan yang semrawut menjorok ke sungai hilang. Namun hal ini tidak bertahan lama, karena lama-kelamaan pun muncul bangunan-bangunan ilegal di bantaran sungai, serta muncul sampah-sampah yang menyumbat saluran Kali Semarang. Oleh karena itu penelitian ini bertujuan untuk mengetahui penerapan konsep waterfront pada Kampung Melayu, Kota Lama, Kampung Pecinan, Kampung Kauman, dan Kampung Sekayu.

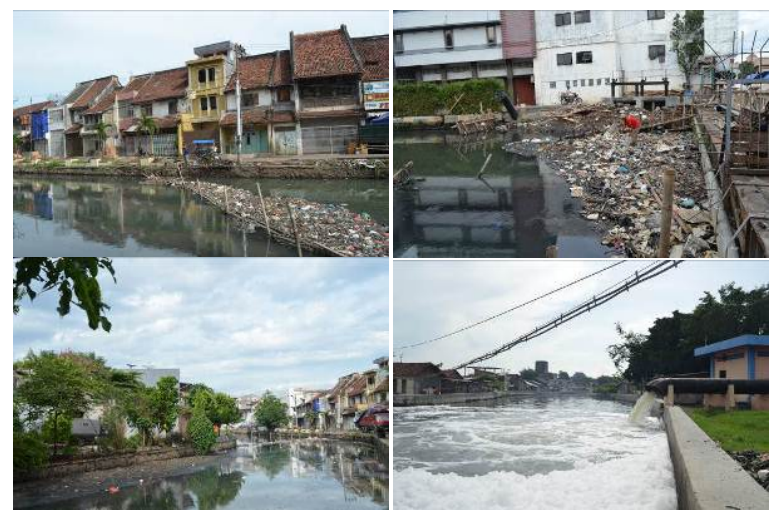

Gambar 2. Kali Semarang 


\section{Teknik, 36 (2), 2015, 63}

\section{Metode Penelitian}

Jenis penelitian yang digunakan dalam penelitian ini menggunakan metode penelitian kualitatif dengan pendekatan rasionalistik (Sugiyono, 2004). Dalam penelitian ini diperlukan deskripsi keadaan yang mendalam dan diperlukan eksplorasi untuk mengidentifikasikan informasi baru pada lokasi penelitian, sesuai dengan metode penelitian kualitatif (Sarwono, 2006); dengan pendekatan rasionalistik yang berarti konsep atau teori yang ada digunakan sebagai jembatan, penjelasan, dan ramalan fenomena yang akan terjadi. Tahapannya antara lain:

a. Memahami Konsep Waterfront

Hal utama yang digunakan untuk memulai penelitian ini adalah pemahaman mendasar mengenai konsep waterfront. Pemahaman mendasar mengenai konsep ini digunakan jembatan, penjelasan, dan ramalan fenomena yang akan terjadi. Juga dilakukan pemahaman mengenai budaya bermukim di tepi sungai.

b. Survei Lokasi

Hal yang kemudian dilakukan adalah pengamatan langsung (survei lokasi) pada Kali Semarang. Pengamatan dilakukan dengan cara menyusuri permukiman sepanjang Kali Semarang mulai dari Kelurahan Pekunden hingga Kelurahan Dadapsari. Peneliti mengamati lingkungan dan masyarakat, serta mengamati fenomena dan gejala yang terjadi. Dari pengamatan tersebut ditemukan bahwa Kali Semarang melewati daerah-daerah etnis yang kaya akan kearifan lokal, seperti Kampung Melayu, Kota Lama, Kampung Pecinan, Kampung Kauman, dan Kampung Sekayu. Ditemukan pula bahwa beberapa permukiman di sepanjang bantaran Kali Semarang telah mengadopsi konsep waterfront.

c. Pencarian Data

Jenis data yang dicari ada 2 (Suryabrata, 2012), yaitu:

1) Data primer, yaitu data yang langsung dikumpulkan oleh peneliti dari sumber pertamanya. Data ini didapatkan dengan pertanyaan mendalam kepada key person dan quesioner (Nasution, 1992). Data primer yang didapatkan pada penelitian yaitu sejarah Kali Semarang, sejarah permukiman etnis Kali Semarang, perubahan yang terjadi (jejak sejarah), faktor sosial, faktor ekonomi, faktor budaya, data gambar, dan peta kuno.

2) Data sekunder, biasanya tersusun dalam bentuk dokumen-dokumen, yang diperoleh dari instansi-instansi terkait. Data sekunder yang didapatkan pada penelitian yaitu tata guna lahan yang didapatkan dari DTK Kota Semarang, RTRW Kali Semarang yang didapatkan saat peneliti mengikuti Seminar RTBL Kali Semarang tahun 2013, PERDA, serta peta wilayah dan monografi wilayah yang didapatkan dari kantor-kantor kelurahan setempat. Juga buku dan jurnal/ artikel. d. Analisa Potensi

Setelah melakukan survei lokasi dan mendapatkan data-data pendukung, analisa potensi mulai dilakukan. Analisa potensi dilakukan pada data primer dan data sekunder.

e. Studi Banding

Dilakukan studi banding untuk memperkaya wawasan mengenai hal yang dikaji. Studi banding yang digunakan adalah Sungai Melaka, Malaysia. Peneliti mengunjungi Sungai Melaka, Malaysia pada saat Kuliah Kerja Lapangan Magister Teknik Arsitektur Universitas Diponegoro pada tahun 2013. Sungai yang telah berkonsep waterfront dan dijadikan sebagi tempat wisata yang humanis ini memiliki banyak kesamaan dengan Kali Semarang, sehingga cocok digunakan sebagai studi banding.

\section{f. Analisa Data}

Setelah semua tahap selesai dilakukan, selanjutnya dilakukan analisa data untuk menghasilkan temuan dari penelitian ini. Di tahap ini peneliti akan mengkaji konsep waterfront dengan keadaan permukiman etnis bantaran Kali Semarang, apakah memiliki pengaruh dari konsep waterfront.

\section{Hasil dan Pembahasan}

Hasil temuan yang telah diperoleh setelah melakukan studi literatur, survei lapangan, dan penelitian mendalam adalah berupa time series sebagai berikut:

a. Kampung Melayu

Kampung Melayu pada awal mulanya menggunakan konsep waterfront, dapat diperkuat pula dari Tabel 1. Berdasarkan konsep waterfront dari Wreen (1983), kawasan waterfront berkembang dari arah perairan dan kemudian mulai ramai dikunjungi hingga muncul sarana penunjang. Konsep waterfront pada kampung ini murni berkembang dari arah perairan yakni Kali Semarang yang bermuara ke Laut Jawa, kemudian dibangun sarana penunjangnya yakni Boom Lama yang fungsinya sebagai pintu masuk pelabuhan Kota Semarang. Kemudian area waterfront tersebut menyebar ke arah daratan yakni Kampung Darat. Lalu muncul sarana penunjang lain seperti dermaga kecil, pabean, dan pasar ikan. Hal ini dapat dilihat di Gambar 3.

Jika dikaji dari konsep waterfront oleh Breen (1996), berdasarkan fungsinya, waterfront di Kampung Melayu dapat dikategorikan dalam jenis Working Waterfront, dimana di dalamnya terdapat fungsi-fungsi pelabuhan dan komersial, serta permukiman dan perdagangan. Dapat dilihat dari permukiman di Kampung Melayu yang pada saat itu berorientasi ke arah Kali Semarang karena banyak digunakan sebagai pelabuhan dan tempat pergudangan untuk menyimpan barang dagangan yang dibawa oleh pelayar-pelayar yang datang ke Kota Semarang. 
Tabel 1. Time Series Permukiman Etnis Kali Semarang (Budiman, 1976, 1978; Liem, 1933, Muhammad, 1996; Pratiwo, 2010; Wawancara, 2014; Analisa, 2014)

14 th
15 th

17th

18th

- 1825

Koridor

- Awal abad

17

1

Kedatangan

etnik Arab

untuk

berdagang di

kawasan Kali

Semarang
- 1743

Boom Lama

mulai aktif

sebagai

pelabuhan utama

di Kali

Semarang
Melayu

semakin

- 1873

Baru terbentuk

Dibangun

Kanal Kali

meneruskan

Kali Semarang

\section{- 1708}

Kedudukan

Belanda di Kota

Lama dekat Kali

Semarang

\section{KOTA}

LAMA

3.

PECINAN

- 1403 Cheng

Ho dan warga

Tionghoa datang

ke Semarang

- 1475

Permukiman

pribumi di bukit

Bergota hingga muncul perdagangan dan perkantoran

\section{- 1750}

Perdagangan

meningkat di

sepanjang Kali

Semarang
KAMPUNG

i

• $\mathbf{1 9 8 0}$
Normalisasi
Kali
Semarang

- 1980

Kali bantaran

Kali

Semarang.

- 2014

- 1921

Boom Kecil

aktif sebagai

tempat

bongkar

muat

perdagangan

- 1980

Normalisasi

Kali

Semarang

\section{- 1608}

kedatangan

Belanda

- 1675 Warga

Tionghoa

menempati

Pecinan dekat

Kali

Semarang
- 1850

Perkembangan dan perluasan

Kampung

Pecinan
- 1980

Normalisasi

Kali

Semarang
Bangunan

telah

berkonsep

waterfront

dengan

jalan

inspeksi di

bantaran

Kali

Semarang.

- 2014

Beberapa

bangunan

di bantaran

Kali

Semarang

telah

berkonsep waterfront.

\begin{tabular}{|c|c|c|c|c|c|c|c|}
\hline & & & Semarang. & & & & waterfront. \\
\hline $\begin{array}{c}4 . \\
\text { KAMPUNG } \\
\text { KAUMAN }\end{array}$ & $\begin{array}{l}\text { - } \mathbf{1 4 7 5} \\
\text { Permukiman } \\
\text { pribumi di bukit } \\
\text { Bergota }\end{array}$ & $\begin{array}{l}\text { - Awal abad } \\
\text { 16 Permukiman } \\
\text { pribumi pindah } \\
\text { ke barat Kali } \\
\text { Semarang }\end{array}$ & $\begin{array}{l}\text { - Akhir abad } \\
\text { 17 Masjid } \\
\text { terbakar } \\
\text { karena } \\
\text { pemberontakan } \\
\text { warga } \\
\text { Tiobghoa di } \\
\text { Semarang }\end{array}$ & $\begin{array}{l}\bullet \mathbf{1 7 4 1} \\
\text { Pembangunan } \\
\text { kembali masjid } \\
\text { besar }\end{array}$ & $\begin{array}{l}\text { • } \mathbf{1 8 5 0} \\
\text { Perdagangan } \\
\text { meningkat di } \\
\text { kawasan Kali } \\
\text { Semarang } \\
\text { (Jembatan } \\
\text { Mberok dan } \\
\text { Pasar Johar) }\end{array}$ & $\begin{array}{l}\text { - } \mathbf{1 9 8 0} \\
\text { Normalisasi } \\
\text { Kali } \\
\text { Semarang }\end{array}$ & $\begin{array}{l}\mathbf{2 0 1 4} \\
\text { Beberapa } \\
\text { bangunan } \\
\text { di bantaran } \\
\text { Kali } \\
\text { Semarang } \\
\text { telah } \\
\text { berkonsep } \\
\text { waterfront. }\end{array}$ \\
\hline \multirow[t]{2}{*}{$\begin{array}{c}5 . \\
\text { KAMPUNG } \\
\text { SEKAYU }\end{array}$} & - & $\begin{array}{l}\text { - Awal abad } \\
\text { 16 Penduduk } \\
\text { pribumi mulai } \\
\text { menghuni } \\
\text { Kampung } \\
\text { Sekayu dekat } \\
\text { Kali Semarang }\end{array}$ & $\begin{array}{l}\text { - Awal abad } \\
\text { 17 Kampung } \\
\text { Sekayu } \\
\text { semakin padat } \\
\text { untuk } \\
\text { permukiman }\end{array}$ & $\begin{array}{l}\text { - Awal abad } \\
\mathbf{1 8} \\
\text { Pembangunan } \\
\text { Masjid Sekayu } \\
\text { di tepi Kali } \\
\text { Semarang }\end{array}$ & - & $\begin{array}{l}\text { - } \mathbf{1 9 8 0} \\
\text { Normalisasi } \\
\text { Kali } \\
\text { Semarang }\end{array}$ & $\begin{array}{l}\text { - } \mathbf{2 0 1 4} \\
\text { Beberapa } \\
\text { bangunan } \\
\text { di bantaran } \\
\text { Kali } \\
\text { Semarang } \\
\text { telah } \\
\text { berkonsep } \\
\text { waterfront. }\end{array}$ \\
\hline & \multicolumn{2}{|c|}{ AWAL MASA PERDAGANGAN } & \multicolumn{4}{|c|}{ MASA GEMILANG PERDAGANGAN } & $\begin{array}{c}\text { PASCA } \\
\text { NORMALISASI }\end{array}$ \\
\hline
\end{tabular}




\section{Teknik, 36 (2), 2015, 65}

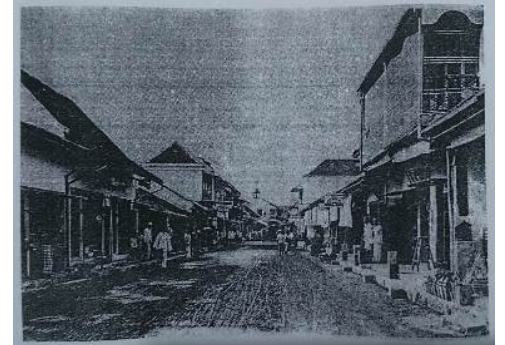

Gambar 3. Fungsi Permukiman dan Perdagangan di Kampung Melayu (Panitia Reuni 100 Tahun HBS V Semarang, 1977)

\section{b. Kota Lama}

Kawasan Kota Lama menggunakan konsep waterfront dari dahulu hingga sekarang, dapat diperkuat pula dari Tabel 1. Berdasarkan konsep waterfront dari Wreen (1983), kawasan waterfront berkembang dari arah perairan dan kemudian mulai ramai dikunjungi hingga muncul sarana penunjang. Letak Kawasan Kota Lama dekat dengan kawasan Boom Lama sebagai pintu masuk pelabuhan Kota Semarang (Gambar 4). Juga terdapat Boom Kecil dan Jembatan Mberok sebagai kawasan yang ramai sebagai aktifitas perekonomian dan pemerintahan di kawasan tersebut. Semakin lama semakin ramai hingga muncul sarana penunjang yakni dibangunnya kantor-kantor perdagangan, kantor bea cukai, kantor pengawas pelayaran,dan juga tempat pergudangan yang digunakan untuk menyimpan barang dagang sebelum didistribusikan ke wilayah Kota Semarang (Seperti ke Pasar Padamaran, ke Pasar Johar, dan wilayah permukiman yang dilewati Kali Semarang) yang berorientasi ke Kali Semarang.

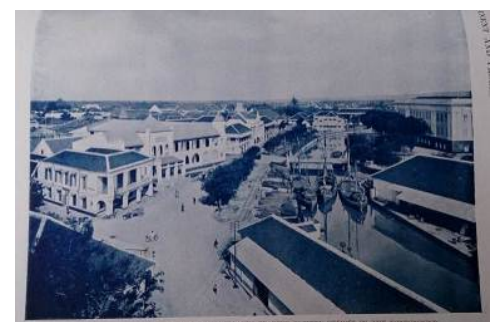

Gambar 4. Boom Kecil dengan Perkantoran Dagang Belanda (Cameron, 1917)

Sedangkan jika dikaji dari konsep waterfront oleh Breen (1996), berdasarkan fungsinya, waterfront Kawasan Kota Lama dahulu dapat dikategorikan dalam jenis Working Waterfront, dimana di dalamnya terdapat fungsi-fungsi pelabuhan dan komersial, serta permukiman dan perdagangan. Namun jika dilihat setelah dilaksanakannya proyek normalisasi, waterfront Kawasan Kota Lama dahulu dapat dikategorikan dalam jenis Historical Waterfront karena dikembangkan ke arah konservasi bangunan sejarah yang ada dalam kawasannya (Gambar 5).
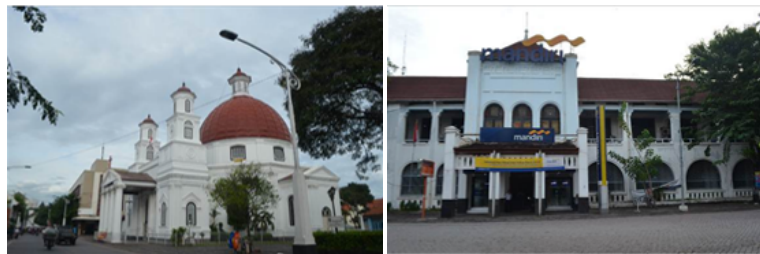

Gambar 5. Bangunan Konservasi di Kota Lama (dokumentasi, 2013)

\section{c. Kampung Pecinan}

Kampung Pecinan pada awal mulanya tidak menggunakan konsep waterfront, karena sebelum proyek normalisasi dilaksanakan, kampung Pecinan yang terletak di tepian Kali Semarang tidak beorientasi langsung ke sungai karena berorientasi ke Bale Kambang sebagai pusat Kota Semarang, saling berhimpitan dan tidak beraturan (Gambar 6). Dapat diperkuat pula dari Tabel 1. Sudah terdapat jalan di tepian Kali Semarang, namun hanya jalan setapak yang hanya muat dilalui pejalan kaki. Ada beberapa bangunan di tepian Kali Semarang yang digunakan sebagai pergudangan.

Perlu diketahui bahwa warga Tionghoa tidak aman untuk tinggal di Semarang pada saat itu, karena mereka buronan Belanda. Rumah etnis Tionghoa pada Kampung Pecinan umumnya memiliki 3 pintu, yakni pintu utama di depan rumah, pintu samping yang bisa menembus ke tetangga, dan pintu belakang yang bisa langsung ke Kali Semarang. Jika dalam keadaan terdesak, mereka dapat melarikan diri langsung ke tetangga maupun langsung ke Kali Semarang (hasil wawancara, 2014). Hal ini juga membuktikan bahwa keadaan sosial politik turut mempengaruhi bentuk permukiman etnis Tionghoa di Kampung Pecinan.

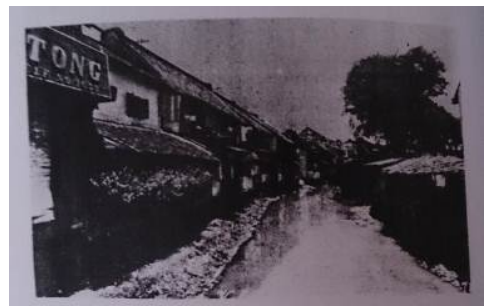

Gambar 6. Kampung Pecinan di Kawasan Klenteng Tay Kak Sie (Budiman, 1979)

Namun setelah dilaksanakan proyek normalisasi, dilihat dari konsep waterfront oleh Breen (1996), berdasarkan fungsinya Kampung Pecinan dapat dikategorikan dalam jenis Historical Waterfront karena dikembangkan ke arah konservasi bangunan sejarah yang ada dalam kawasannya (Gambar 7).

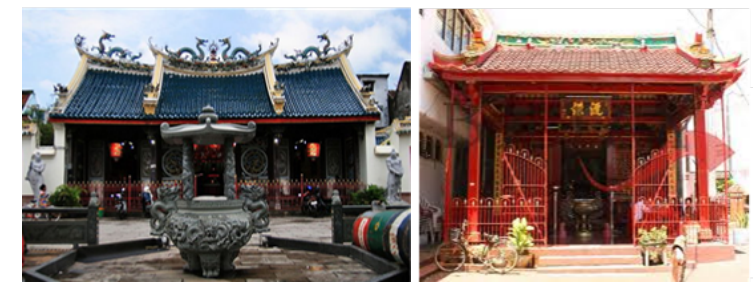

Gambar 7. Bangunan Konservasi di Kampung Pecinan (dokumentasi, 2013) 


\section{Teknik, 36 (2), 2015, 66}

\section{d. Kampung Kauman}

Pada tabel tersebut dapat dilihat bahwa Kampung Kauman pada awal mulanya tidak menggunakan konsep waterfront, karena sebelum proyek normalisasi dilaksanakan, kampung Kauman yang terletak di tepian Kali Semarang tidak beorientasi ke sungai, saling berhimpitan, dan tidak beraturan. Hanya pada sebagian kecil kampung Kauman yakni ex Sumenepan saja yang bangunannya menghadap ke sungai karena banyak difungsikan sebagai tempat bongkar muat dan pergudangan. Dapat diperkuat pula dari Tabel 1.

Namun setelah dilaksanakan proyek normalisasi, dilihat dari konsep waterfront oleh Breen (1996), berdasarkan fungsinya Kampung Kauman dapat dikategorikan dalam jenis Mixed-Used Waterfront karena merupakan kombinasi dari permukiman, perkantoran, perdagangan, dan tempat kebudayaan (Gambar 8).

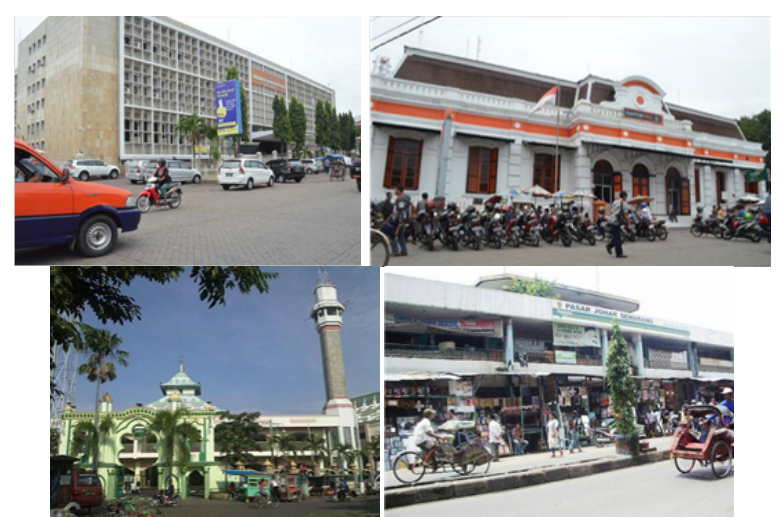

Gambar 8. Kombinasi Perkantoran, Kebudayaan, dan Perdagangan di Kampung Kauman (dokumentasi, 2013)

\section{e. Kampung Sekayu}

Kampung Sekayu pada awal mulanya tidak menggunakan konsep waterfront, karena sebelum proyek normalisasi dilaksanakan, kampung Sekayu yang terletak di tepian Kali Semarang tidak berorientasi ke sungai, saling berhimpitan, dan tidak beraturan. Bangunan yang ada lebih berorientasi pada jalan lingkungan yang ada pada kampung tesebut. Sudah terdapat jalan di tepian Kali Semarang, namun hanya jalan setapak yang hanya muat dilalui pejalan kaki. Dapat diperkuat pula dari Tabel 1.

Namun setelah dilaksanakan proyek normalisasi, dilihat dari konsep waterfront oleh Breen (1996), berdasarkan fungsinya Kampung Sekayu dapat dikategorikan dalam jenis Mixed-Used Waterfront karena merupakan kombinasi dari permukiman, perkantoran, kebudayaan, dan rekreasi (Gambar 9).

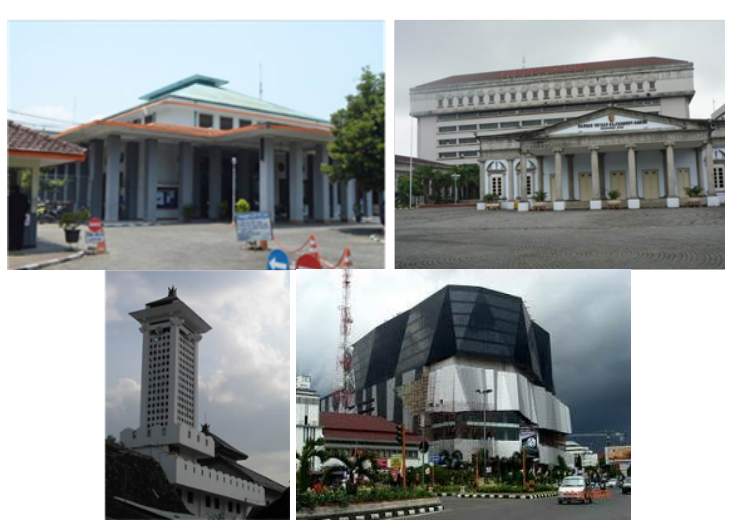

Gambar 9. Kombinasi Perkantoran, Kebudayaan, dan Rekreasi di Kampung Sekayu (dokumentasi, 2013)

\section{Kesimpulan}

Dari studi literatur, survei lapangan, dan pertanyaan mendalam, didapatkan bahwa dalam posisinya, Kali Semarang yang merupakan sungai bersejarah bagi Kota Semarang, dilalui beberapa kampung etnis, yakni Kampung Melayu, Kawasan Kota Lama, Kampung Pecinan, Kampung Kauman, dan Kampung Sekayu. Berikut merupakan penjelasannya :

- Kampung Melayu pada awal mulanya menggunakan konsep waterfront. Hal ini disebabkan karena letak kampung ini di dalam kawasan pelabuhan Boom Lama dan Kali Baru, sehingga secara alami muncullah fungsi waterfront sebagai tempat pelabuhan, pergudangan, dan perdagangan di sana.

- Kawasan Kota Lama pada awal mulanya menggunakan konsep waterfront. Hal ini disebabkan karena kawasan tersebut terletak di dekat Boom Kecil dan jembatan Mberok yang merupakan area pelabuhan serta perdagangan. Banyak pula kantor dan tempat pergudangan. Selain itu, Kota Lama juga merupakan "Kota Belanda" yang memang mengadopsi konsep waterfront dari tempat asalnya sejak pertama didirikan.

- Kampung Pecinan pada awal mulanya tidak menggunakan konsep waterfront. Fungsi Kali Semarang yang pada saat itu digunakan untuk transportasi tidak dijadikan nilai tambah untuk orientasi bangunan karena awal mulanya orientasi bangunan pada Kampung Pecinan ini terletak di tengah kawasan, yakni ke arah Bale Kambang. Kampung Pecinan mulai menggunakan konsep waterfront setelah dilaksanakannya proyek normalisasi Kali Semarang.

- Kampung Kauman pada awal mulanya tidak menggunakan konsep waterfront. Hanya pada sebagian kecil kampung Kauman yakni ex Sumenepan saja yang bangunannya menghadap ke sungai karena banyak difungsikan sebagai tempat bongkar muat dan pergudangan. Fungsi Kali Semarang yang pada saat itu digunakan untuk transportasi tidak dijadikan nilai tambah untuk orientasi bangunan. Kampung Kauman mulai menggunakan konsep waterfront setelah 


\section{Teknik, 36 (2), 2015, 67}

dilaksanakannya proyek normalisasi Kali Semarang.

- Kampung Sekayu pada awal mulanya tidak menggunakan konsep waterfront. Fungsi Kali Semarang yang pada saat itu digunakan untuk transportasi tidak dijadikan nilai tambah untuk orientasi bangunan karena hanya digunakan sebagai muka belakang. Kampung Sekayu mulai menggunakan konsep waterfront setelah dilaksanakannya proyek normalisasi Kali Semarang.

\section{Ucapan Terima Kasih}

Terima kasih Allah SWT, keluarga besar, Pengajar Magister Teknik Arsitektur Undip, serta pihak-pihak terkait yang telah membantu penyusunan jurnal ini. Tidak lupa pula Fakultas Teknik Undip yang telah mendanai keberlangsungan jurnal ini.

\section{Daftar Pustaka}

Breen, Ann, and Dick Rigby. (1996). The New Waterfront: A Worldwide Urban Success Story. Great Britain: Thames \& Hudson.

Breen, Ann, and Dick Rigby. (1994). Waterfront, Cities Reclaim Their Edge. New York: Mc. Graw Hill.

Budiman, Amen. (1976). Boom Lama dan Boom Baru. Suara Merdeka, Jumat, 2 April 1976.

Budiman, Amen. (1978). Semarang Riwayatmu Dulu. Semarang: Percetakan Satya Wacana.
Budiman, Amen. (1979). Semarang Juwita. Semarang: Tanjung Sari.

Cameron, W.H Morton. (1917). Present Day Impressions od The Far East and Prominent and Progressive Chinese at Home and Abroad. London: The Globe Encyclopedia Company.

Liem, Thian Joe. (1933). Riwajat Semarang (Dari Djamannja Sam Poo sampe terhapoesnja Kongkoan). Semarang: Boekhandel Ho Kim Yoe.

M. Wrenn, D. (1983). Urban Waterfront Development. Washington DC: ULI - The Urban Land Institute.

Muhammad, Djawahir. (1996). Semarang Sepanjang Jalan Kenangan. Semarang: Pemda Kota Semarang.

Nasution, M.A. (1992). Metode Penelitian Naturalistik - Kualitatif. Bandung: Tarsito.

Panitia Reuni 100 Tahun HBS V Semarang. (1977). Semarang Tempo Doeloe, 100 Tahun HBS V Semarang 1877-1977. Semarang.

Pratiwo. (2010). Arsitektur Tradisional Tionghoa dan Perkembangan Kota. Yogyakarta: Penerbit Ombak.

Sarwono, Jonathan. (2006). Metode Penelitian Kuantitatif dan Kualitatif. Yogyakarta: Graha Ilmu.

Sugiyono. (2004). Metode Penelitian Bisnis. Bandung: CV. Alfabeta.

Suryabrata, Sumadi. (2012). Metodologi Penelitian. Jakarta: PT Raja Grafindo Persada.

www.googleearth.com. Diakses tanggal 16 April 2013. 